\title{
Commentary: Massachusetts exceptionalism
}

\author{
Craig R. Smith, MD
}

\footnotetext{
From the Department of Surgery, Johnson \& Johnson Distinguished Professor, Valentine Mott Professor of Surgery, Vagelos College of Physicians \& Surgeons of Columbia University, Columbia University Irving Medical Center of New York Presbyterian Hospital, New York, NY.

Disclosures: Author has nothing to disclose with regard to commercial support.

Received for publication Dec 27, 2018; revisions received Dec 27, 2018; accepted for publication Dec 28, 2018; available ahead of print March 4, 2019.

Address for reprints: Craig R. Smith, MD, Columbia University Irving Medical Center of New York Presbyterian Hospital, 177 Fort Washington Ave, Milstein Building 7-435, New York, NY 10032 (E-mail: crs2@cumc. columbia.edu).

J Thorac Cardiovasc Surg 2019;158:125-6 $0022-5223 / \$ 36.00$

Copyright (c) 2019 by The American Association for Thoracic Surgery

https://doi.org/10.1016/j.jtcvs.2018.12.103
}

Mandatory public reporting has been generally unpopular since it began in New York in 1991, and it remains controversial today. Opponents emphasize a variety of purported evils (gaming, shaming, risk-aversion, meaningless distinctions, etc). Shahian and colleagues ${ }^{1}$ show that outcomes for isolated coronary artery bypass grafting procedures in Massachusetts improved between 2003 and 2014 and were significantly better than the outcomes reflected in the Society of Thoracic Surgeons database over the same period. This coincides with the introduction of mandatory public reporting in Massachusetts, and readers should not miss the implication that the improvement is attributable to that policy. The authors have pointed out several ways in which the process of producing data for mandatory public reporting might contribute to collaborative quality improvement efforts, including providing re-entry pathways for outliers. The authors have mollified some reviewers by soft-pedaling the link between public reporting and outcome improvement, acknowledging that there are no data from a comparison period before 2003 .

They hold their ground against those who would rather attribute the Massachusetts mortality decline to risk aversion-there is simply no evidence for avoidance of high-risk cases in this experience. As the authors discuss, the published evidence for risk aversion in coronary artery bypass grafting is inconclusive at best. Even though well documented in percutaneous coronary interventions for complicated acute myocardial infarctions (see the authors' 5 references), risk aversion among cardiac surgeons is not the pernicious and inevitable consequence of public reporting that many like to claim.

The far more prevalent evil twin of risk aversion is risk-exaggeration through gaming. Readers should note that upcoding of risk factors was steadily reduced by the kind of collaborative rigorous oversight and genuine auditing that characterizes conscientious public reporting definitions.

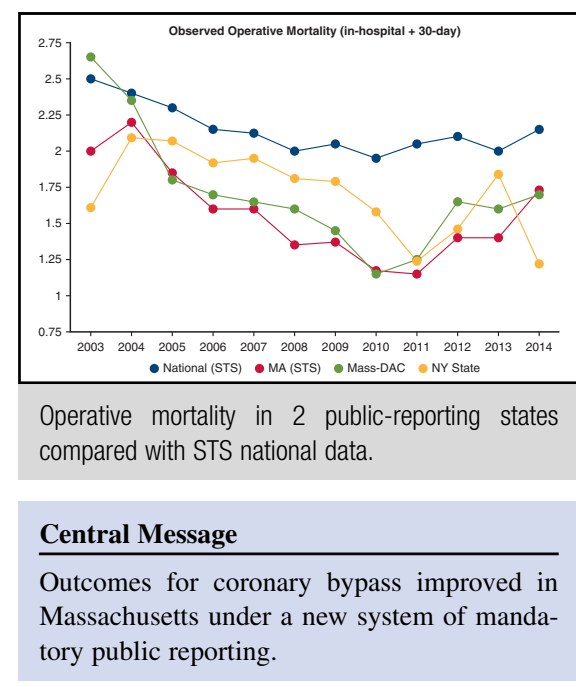

See Article page 110.

efforts like that in Massachusetts. The experience in New York was very similar (Figure 1), particularly in the early years. The results we share with the public should be accurate, complete, and underpinned by unambiguous

These results will not prevent many physicians and institutions from worrying about referrals being influenced by unimportant or misleading differences in operative mortality broadcast in various media. After 27 years practicing cardiac surgery under mandatory institution and individual-surgeon public reporting in New York State,

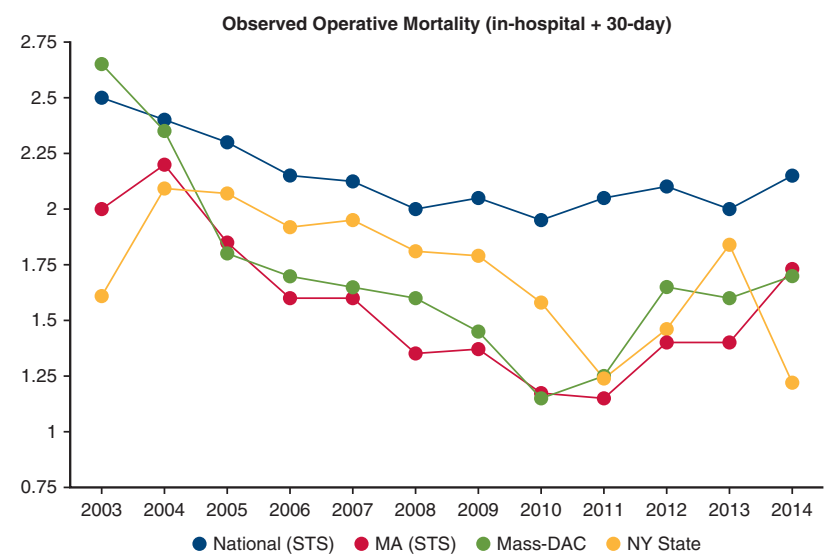

FIGURE 1. Operative mortality in 2 public-reporting states compared with STS national data. STS, Society of Thoracic Surgeons; Mass-DAC, Massachusetts Data Analysis Center. 
I've stopped worrying. I have come to believe that patients and referring physicians are insightful enough to understand that overall performance in a complex task like cardiac surgery can't be reduced to a single statistic, any more than the greatness of a baseball player like Derek Jeter can be reduced to a batting average. I have made myself unpopular in Europe by arguing this point at much greater length ${ }^{2}$ in another journal. Here, I will offer just one brief analogy. More than 500,000 errors have been committed in the history of baseball. ${ }^{3}$ Who do you suppose dominates the list of error-committers? Shortstops, plus a smattering of second and third basemen. In other words, the best defensive athletes in the game. Why all the errors? Because of frequency multiplied by difficulty - they face the greatest number of the most difficult plays. Sound familiar?

\section{References}

1. Shahian DM, Torchiana DF, Engelman DT, Sundt TM, D'Agostino RS, Lovett AF, et al. Mandatory public reporting of cardiac surgery outcomes: the 2003 to 2014 Massachusetts experience. J Thorac Cardiovasc Surg. 2019;158: 110-24.e9.

2. Smith CR. The big debate: this house believes that surgeons' outcomes should be published in the lay press. Int J Surg. 2006;4:199-203.

3. Hoffman B. Baseball's 500,000th Error Finds Jose Reyes. New York Times; September 18, 2012: B11. 